\title{
Functional Implications of Neurotransmitter Expression during Axonal Regeneration: Serotonin, But Not Peptides, Auto-Regulate Axon Growth of an Identified Central Neuron
}

\author{
Cornelis E. Koert, ${ }^{1}$ Gaynor E. Spencer, ${ }^{2}$ Jan van Minnen, ${ }^{1}$ Ka Wan Li, ${ }^{1}$ Wijnand P. M. Geraerts, ${ }^{1}$ \\ Naweed I. Syed, ${ }^{2}$ August B. Smit, ${ }^{1}$ and Ronald E. van Kesteren ${ }^{1}$ \\ ${ }_{1}^{1}$ Department of Molecular and Cellular Neurobiology, Research Institute Neurosciences, Vrije Universiteit, 1081 HV \\ Amsterdam, The Netherlands, and ${ }^{2}$ Respiratory and Neuroscience Research Groups, Faculty of Medicine, University of \\ Calgary, Alberta, Canada T2N 4N1
}

We studied the regenerative properties of one of two electrically coupled molluscan neurons, the serotonergic cerebral giant cells (CGCs) of Lymnaea stagnalis, after axotomy. The CGCs play a crucial role in feeding behavior, and when both cells are disconnected from their target neurons, animals no longer feed. When one CGC was permanently disconnected from its targets and the other was reversibly damaged by a nerve crush, the latter one regenerated over a period of 2 weeks to reform functional synapses with specific target neurons. At the same time, recovery of the feeding behavior was observed. After the crush, neuropeptide gene expression in the CGC was downregulated to $\sim 50 \%$. Serotonin synthesis, on the other hand, remained unaffected, suggesting that serotonin might have an active role in regeneration. In primary neuron culture, CGCs failed to extend neurites in the presence of serotonin; in cells that extended neurites in the absence of serotonin, focally applied serotonin, but not neuropeptides, induced growth cone collapse. Using serotonin-sensitive sniffer cells, we show that CGC neurites and growth cones release serotonin in culture. Finally, both the spontaneous and stimulation-induced release of serotonin from CGCs in culture resulted in growth cone collapse responses that could be blocked by the serotonin receptor antagonist methysergide. Our data suggest that autoreleased serotonin is inhibitory to CGC neurite outgrowth in vitro. During regeneration in vivo, serotonin release might finetune axon guidance and branching by inducing local collapse responses in extending neurites.

Key words: neuronal regeneration; neurite outgrowth; synapse formation; behavioral recovery; serotonin; myomodulin; Lymnaea stagnalis
Besides a well established role in neuronal communication, neurotransmitters have important functions in neuronal outgrowth, both during development and after injury (Mattson, 1988). Observations that neurotransmitters are expressed during early brain development, long before synaptic transmission occurs, suggest that neurotransmitters may function as regulators of neurite outgrowth (Filogamo and Marchisio, 1971). Serotonergic fibers in particular are among the earliest afferent pathways in the developing nervous system (Lauder and Bloom, 1974; Lauder, 1990), suggesting a role for serotonin in brain development.

Three modes of action have been postulated for neurotransmitters as regulators of axon outgrowth. Firstly, neurotransmitters may have trophic effects on the tissues surrounding regenerating neurons, thus creating a growth-permissive environment (Lauder, 1993; Hökfelt et al., 1994). This has been demonstrated for vasoactive intestinal peptide during the regeneration of primary sensory neurons (Said and Mutt, 1970; Magistretti et al.,

\footnotetext{
Received Dec. 6, 2000; revised April 25, 2001; accepted May 15, 2001.

This work is supported by the Netherlands Foundation for Scientific Research (NWO), the Royal Dutch Academy of Sciences (KNAW), Human Frontier Science Program Organization Grant RG0045/1997B, Medical Research Council (Canada), and Natural Sciences and Engineering Research Council of Canada. N.I.S. was supported by NWO Visitors Grant B88-236. We thank Dr. Cees Janse, Ellen van Kesteren, Roel van der Schors, and Wali Zaidi for excellent technical support.

GenBank accession numbers: AF129397 (SPTR cDNA); AF129815 (LTRH cDNA).

Correspondence should be addressed to Dr. R. E. van Kesteren, Department of Molecular and Cellular Neurobiology, Faculty of Biology, De Boelelaan 1087, 1081HV Amsterdam, The Netherlands. E-mail: revankes@bio.vu.nl.

Copyright (C) 2001 Society for Neuroscience $0270-6474 / 01 / 215597-10 \$ 15.00 / 0$
}

1981; Gressens et al., 1993, 1997). Secondly, neurotransmitters released by one neuron may selectively affect the outgrowth of other neurons (Lipton and Kater, 1989; Lauder, 1990). Acetylcholine, for instance, attracts neurites of Xenopus spinal neurons (Zheng et al., 1994), whereas it inhibits neurite outgrowth of rat retinal ganglion cells (Lipton et al., 1988). Thirdly, neurotransmitters may auto-regulate axon outgrowth of the same neurons from which they are released (Budnik et al., 1989; WhitakerAzmitia et al., 1990). For instance, Xenopus spinal neurons respond to auto-released acetylcholine with growth cone turning (Erskine and McCaig, 1995).

In peripheral nerve regeneration models, it is suggested that transmitters that are involved in regeneration are continuously expressed during the regenerative response, whereas transmitters that are only involved in neurotransmission are downregulated (Hökfelt et al., 1994; Zigmond and Sun, 1997; Zigmond, 1998). The problem with peripheral nerve regeneration models is that they involve heterogeneous populations of neurons with varying transmitter phenotypes, and that not all neurons regenerate equally well. Consequently, it is not possible to correlate changes in neurotransmitter expression in a single neuron to the regenerative capacities of that same neuron in vivo; neither is it possible to test in vitro the effects of the transmitters of interest on axon regeneration of that particular neuron.

The cerebral giant cells (CGCs) of the Lymnaea CNS have particular advantages to study the role of neurotransmitters in regeneration. The CGCs are separated from their target neurons in the buccal ganglia by a large nerve-like connective that is well 
accessible to various lesion paradigms (McCrohan and Benjamin, 1980a; Goldschmeding et al., 1981; Croll and Chiasson, 1989). The CGCs are the only source of serotonin in the buccal ganglia, allowing specific immunocytochemical detection of regenerating CGC neurites. The electrophysiological properties of the CGCs are well described (Benjamin and Rose, 1979; McCrohan and Benjamin, 1980b; Kemenes and Elliott, 1994; Yeoman et al., 1996), providing accurate parameters of functional regeneration. Finally, CGCs can easily be cultured in vitro to test the roles of individual transmitters in axon regeneration. The aim of this study is to determine the auto-regulatory roles of endogenous transmitters in CGC neurite outgrowth and regeneration.

\section{MATERIALS AND METHODS}

Animals. Stocks of Lymnaea stagnalis were maintained in the laboratory under standard conditions (van der Steen, 1969). Snails were fed lettuce ad libitum, unless otherwise indicated. Adult animals (shell length, 30-35 $\mathrm{mm}$ ) were used, except in neuron isolation and culture experiments for which 2-month-old animals (shell length, $\sim 22 \mathrm{~mm}$ ) were used.

Surgical procedure. Animals were anesthetized by injecting 1-1.5 ml of $60 \mathrm{~mm} \mathrm{MgCl}{ }_{2}$ into the foot. A small incision was made in the dorsal head region, and the esophagus was gently pulled out using a tiny hook, exposing the cerebral and buccal ganglia. Cerebral-buccal connectives (CBCs) were crushed halfway at the bifurcation point of the salivary nerve using a Dumont \# 5 forceps (Fine Science Tools, Foster City, CA). To ensure a standard crush pressure, a piece of silicon tubing (length, 2 $\mathrm{cm}$; outer diameter, $2.2 \mathrm{~mm}$; wall thickness, $0.4 \mathrm{~mm}$ ) was placed at the base of one of the tips of the forceps, causing the tips of the forceps to open when the pressure applied reached a certain threshold. Complete transsections were performed at the same place. After the operation, the esophagus was gently pushed back into the head, and the wound was rinsed using HEPES-buffered saline (HBS) (in mm: $30 \mathrm{NaCl}, 10$ $\mathrm{NaCH}_{3} \mathrm{SO}_{4}, 5 \mathrm{NaHCO}_{3}, 1.7 \mathrm{KCl}, 4 \mathrm{CaCl}_{2}, 1.5 \mathrm{MgCl}_{2}, 10 \mathrm{HEPES}, \mathrm{pH}$ 7.8 , adjusted with $\mathrm{NaOH}$ ). Sham operations were performed in the same way, with the exception that the connectives were not crushed or cut. After the operation, animals were placed back in flow-through jars and maintained under standard laboratory conditions.

Quantification of feeding behavior. Operated animals were kept individually in jars that were provided with a fakir bed to prevent coprophagy. The animals were provided with fresh lettuce every second day. After $2 \mathrm{~d}$, the remaining lettuce was removed, and the surface area of consumed lettuce was calculated using computer imaging software. After removal of the remaining lettuce, the animals were provided with fresh lettuce again.

Electrophysiological recordings. Central ganglia were pinned down in a recording chamber that was filled with high $\mathrm{Mg}^{2+} /$ high $^{-2}{ }^{2+} \mathrm{HBS}$ (in mm: $16 \mathrm{NaCl}, 10 \mathrm{NaCH}_{3} \mathrm{SO}_{4}, 5 \mathrm{NaHCO}_{3}, 1.7 \mathrm{KCl}, 10 \mathrm{CaCl}_{2}, 10 \mathrm{MgCl}_{2}$, 10 HEPES, $\mathrm{pH} 7.8$, adjusted with $\mathrm{NaOH}$ ). Electrophysiological recordings were performed with standard equipment for simultaneous intracellular recording and current injection. Glass microelectrodes (GC150F-10; Clark Electromedical Instruments, Reading, UK) were filled with $0.5 \mathrm{M}$ $\mathrm{KCl}$ and had resistances of $10-50 \mathrm{M} \Omega$. The amplifiers were compensated for the electrode resistance just before the start of the measurements. Synaptic contacts between the CGC and B4 were measured by injecting depolarizing current pulses in the CGC soma and recording the membrane potential responses of the CGC and B4 on a 2200S chart recorder (Gould, Cleveland, $\mathrm{OH}$ ).

Whole-mount immunocytochemistry. Cerebral and buccal ganglia were incubated in $0.5 \%$ type XIV protease (Sigma, St. Louis, MO) for $30 \mathrm{~min}$ and fixed overnight at $4{ }^{\circ} \mathrm{C}$ in a $1 \%$ paraformaldehyde $/ 1 \%$ acetic acid solution. The tissue was rinsed in Supermix $(50 \mathrm{~mm}$ Tris-HCl, $\mathrm{pH}$ 7.6, $150 \mathrm{~mm} \mathrm{NaCl}$, and 2\% Triton X-100) for $8 \mathrm{hr}$, replacing the buffer every hour, and incubated overnight in anti-serotonin primary antibody (kindly provided by Dr. H. W. M. Steinbusch, University of Maastricht, Maastricht, The Netherlands) diluted 1:250 in Supermix. Then, the tissue was rinsed in Supermix without Triton X-100 for $6 \mathrm{hr}$ (replacing the buffer every hour) and incubated overnight in fluorescein-labeled swine-antirabbit secondary antibody (Dako, Glostrup, Denmark) diluted 1:50 in Supermix. The tissue was rinsed in $50 \mathrm{~mm}$ Tris- $\mathrm{HCl}, \mathrm{pH} 7.6,150 \mathrm{~mm}$ $\mathrm{NaCl}$ for $4 \mathrm{hr}$ (replacing the buffer every hour), mounted in $1 \%$ ethylenediamine and $75 \%$ glycerol, and viewed with a Zeiss LSM 401 inverted laser scanning microscope (Zeiss, Jena, Germany).
Mass spectrometry. Individual CGCs were dissected under a microscope using tiny hooks. A glass pipette (tip diameter, $\sim 100 \mu \mathrm{m}$ ) was used to remove the cell and directly transfer it into $1 \mu \mathrm{l}$ of matrix solution (10 $\mathrm{mg}$ of 2,5-dihydroxybenzoic acid dissolved in $1 \mathrm{ml}$ of $7.5 \mathrm{~mm}$ trifluoroacetic acid in $30 \%$ acetonitrile) on a stainless steel target. After the sample was dried, the target was placed into a laboratory-built matrixassisted laser desorption ionization mass spectrometer (MALDI-MS) for analysis. The spectra were externally calibrated using the masses of four identified molecular ions, yielding an accuracy of 0.01-0.05\% (Jiménez et al., 1994).

Extraction and purification of peptides. Approximately 1200 CGCs were dissected, boiled in $0.1 \mathrm{M}$ acetic acid for $8 \mathrm{~min}$, and centrifuged for 10 $\min$ at $4^{\circ} \mathrm{C}$. The supernatant was separated on a reverse phase HPLC (rpHPLC) system (Gynkotek, Germering, Germany). A Nucleosil C18 column $(5 \mu \mathrm{m}, 250 \times 2.1 \mathrm{~mm}$; Hichrom, Reading, UK) was used, and separation was achieved with the following protocol: 5 min $95 \%$ solvent A (7.5 mM trifluoroacetic acid) $-5 \%$ solvent B ( $7.0 \mathrm{~mm}$ trifluoroacetic acid in $60 \%$ acetonitrile), a 65 min linear gradient starting with $95 \%$ solvent A-5\% solvent $\mathrm{B}$ and ending with $100 \%$ solvent $\mathrm{B}$, followed by $10 \mathrm{~min}$ $100 \%$ solvent $\mathrm{B}$. The flow-rate was $300 \mu \mathrm{l} / \mathrm{min}$, and $1 \mathrm{~min}$ fractions were collected. Fractions 40-46 were pooled and subjected to the following rpHPLC protocol: a 60 min linear gradient starting with $70 \%$ solvent $\mathrm{A} / 30 \%$ solvent $\mathrm{B}$ and ending with $30 \%$ solvent $\mathrm{A} / 70 \%$ solvent $\mathrm{B}$, followed by a 5 min linear gradient starting with $30 \%$ solvent $\mathrm{A} / 70 \%$ solvent B and ending with $100 \%$ solvent B. The flow-rate was $300 \mu \mathrm{l} / \mathrm{min}$, and $150 \mu \mathrm{l}$ fractions were collected. From each HPLC fraction, $0.5 \mu \mathrm{l}$ was used for MALDI-MS analysis as described above. HPLC fractions of interest were reduced to $\sim 20 \mu \mathrm{l}$ in a speedvac and used for amino acid sequencing on a 473 pulse liquid sequencer (Applied Biosystems, Foster City, CA). On the basis of the amino acid sequences obtained, peptides were synthesized by Fluorenylmethoxycarbonyl and t-butoxycarbonyl chemistry on an ABI 432A peptide synthesizer (Applied Biosystems) and used to show co-elution with the native peptides on HPLC.

CDNA cloning. Based on the partial amino acid sequence of one of the novel CGC peptides (ERYMGICM), a degenerate sense primer (5'-CGAAGCTTGA (A,G) (A,C)GNTA(CT)ATGGGNAT(A,T,C)TG(C,T) ATG-3') was designed and used to PCR-screen a cerebral ganglia-specific $\lambda$ ZAPII cDNA library (Smit et al., 1992) in combination with primers directed to either one of the $\lambda$ vector arms, EV2 (5'-CGCCAGGGTTTTCCCAGTCACGAC-3') and EV3 (5'-AGCGGATAACAATTT CACACAGGA-3'). PCR products were reamplified using the same degenerate primer in combination with nested primers directed to each $\lambda$ arm, T77 (5'-GCGTAATACGACTCACTATAGGGCGA-3') and T33 (5'-GCGCAATTAACCCTCACT AAAGG-3'), respectively. Amplified cDNA was digested with EcoRI and HindIII, cloned in pBluescript KS, and sequenced. After verification of the sequence, the amplified cDNA fragment was used as a probe in a filter lift screen of the cerebral ganglia $\lambda$ ZAPII cDNA library as described earlier (van Kesteren et al., 1995). After in vivo excision, the cDNA insert of one of the positive clones was sequenced on both strands.

Quantitative in situ hybridization. cDNA fragments for the Lymnaea myomodulin prohormone and Lymnaea tryptophane hydroxylase (LTRH) were generated by PCR and subcloned into M13 (Koert, 2000). SPTR, myomodulin, and LTRH templates for in vitro transcription were generated by PCR using M13-based primers extended with T3 and T7 promoter sequences, respectively. Specific $\left[\alpha^{-35}\right.$ S-]UTP-labeled RNA probes were generated from $150 \mathrm{ng}$ of each PCR fragment. In vitro transcriptions were performed at $37^{\circ} \mathrm{C}$, using either T3 or T7 RNA polymerase (Boehringer Mannheim, Mannheim, Germany) containing 1 mM GTP/ATP/CTP and $3 \mu \mathrm{M}\left[\alpha^{-}{ }^{35}\right.$ S $]$ UTP as described (Smit et al., 1996). Probes had specific activities between $1 \times 10^{7}$ and $1 \times 10^{8}$ $\mathrm{cpm} / \mu \mathrm{g}$ RNA. Cerebral and pedal ganglia were dissected from the CNS at days $1,3,5$, and 14 after the operation and fixed overnight in $1 \%$ paraformaldehyde- $1 \%$ acetic acid. After dehydration, the tissue was embedded in paraffin, and parallel $7 \mu \mathrm{m}$ sections were cut and adhered to $0.5 \%$ gelatin $-0.5 \%$ chromalum-coated slides. Hybridization, washing, and visualization were performed as described (Spijker et al., 1997). Steady-state mRNA levels were determined by measuring the silver grain density in the total cytoplasmic area of individual CGCs in the two consecutive sections that contained the largest portion of the nucleus. Silver grain densities were measured using a computerized image analysis system (VIDAS; Kontron Electronic, Munich, Germany). In the same sections, the background silver grain density was measured in areas devoid of specific labeling and subtracted from the silver grain density measured in the cytoplasm of positive neurons. To account for differ- 
ences in hybridization signal between sections and/or animals, identifiable neurons in the pedal ganglia that were positive for either probe (i.e., right pedal dorsal 1 for the myomodulin probe, left pedal dorsal 1 for the LTRH probe, and two identifiable neurons located rostroventrally in the pedal ganglia for the SPTR probe) and unlikely to be affected by the operation procedure, were measured and used as an internal standard. For each probe, the mean silver grain density of the left CGC was divided by the mean silver grain density of the corresponding standard neuron.

Quantitative PCR. Primers for quantitative PCR (Q-PCR) analysis of SPTR (sense: 5'-AACGCTACATGGGAATCTGCAT-3'; antisense: 5'-GCATCACCTCTCCAGGACTTCTTA-3'), myomodulin (sense: 5' ACGGACACTTTGGAGGAACTGA-3'; antisense: 5'-GATTTACCGCCTGCCAAACA-3'), and LTRH (sense: 5'-AAATATGCGCACGGTACTGAGATAC-3'; antisense: 5'-AGCTTCATGAGTTCACGGAAAACTA-3') mRNAs were designed using PrimerExpress v1.0 (Applied Biosystems). Total RNA was isolated from five buccal ganglia of shamoperated and crush-cut-operated animals at day 5 after the operation, reverse transcribed into cDNA using SuperScript II (Life Technologies, Rockville, MD), and used as a template in a Q-PCR experiment. The ABI 7700 Sequence Detection System (Applied Biosystems) was used with CYBR-Green as the reporter dye. All reactions were performed according to the manufacturer's instructions.

Cell culture. Defined medium (DM) consisted of serum-free $50 \%$ Liebowitz L-15 medium (Life Technologies) containing: $40.0 \mathrm{~mm} \mathrm{NaCl}$, $1.7 \mathrm{~mm} \mathrm{KCl}, 4.1 \mathrm{mM} \mathrm{CaCl}_{2}, 1.5 \mathrm{mM} \mathrm{MgCl}_{2}, 10.0 \mathrm{~mm}$ HEPES, pH 8.1, 150 $\mu \mathrm{g} / \mathrm{ml}$ L-glutamine, $54 \mu \mathrm{g} / \mathrm{ml} \mathrm{D}$-glucose, and $25 \mu \mathrm{g} / \mathrm{ml}$ gentamicin. CGCs and B4 cells (i.e., identified follower neurons of the CGCs that respond to serotonin) were isolated and cultured as described earlier (Syed et al., 1990). Cells were cultured for $24 \mathrm{hr}$ in brain-conditioned DM (Wong et al., 1981), after which time extensive neurite outgrowth had occurred.

Growth cone collapse assays. The motility and morphology of individual growth cones was monitored for at least $20 \mathrm{~min}$ before the experiments using time-lapse photography. A micropipette (diameter, $\sim 5 \mu \mathrm{m}$ ) containing $10^{-5} \mathrm{M}$ serotonin (Sigma), $10^{-5} \mathrm{M}$ ERYM peptide, or $10^{-5} \mathrm{M}$ SPTR peptide (all dissolved in DM) was placed at a distance of 100-200 $\mu \mathrm{m}$ from the growth cone. Substances were pressure-ejected (model 5242 pressure ejector; Eppendorf Scientific, Westbury, NY) at $5 \mathrm{sec}$ pulses, 6-10 psi. The motility and morphology of the growth cones was monitored then for up to $3 \mathrm{hr}$. For control experiments, DM was applied to the growth cones for a period of $3 \mathrm{~min}$. In addition, collapse responses were measured after spontaneous release of serotonin, induced release of serotonin (intracellular stimulation by $0.2 \mathrm{nA}$ current injection for $2 \mathrm{sec}$, resulting in 5-10 action potentials), and induced release in the presence of the serotonin receptor antagonist methysergide $\left(10^{-5} \mathrm{M}\right)$.

Sniffer cell assays. B4 neurons were freshly isolated and plated in culture dishes containing hemolymph to prevent adhesion to the substrate. After $2 \mathrm{hr}$, the B4 cells were transferred to culture dishes containing growing CGCs, impaled with an intracellular recording electrode containing saturated $\mathrm{K}_{2} \mathrm{SO}_{4}$, and placed close to, but not in contact with, a CGC neurite or growth cone. The CGC was then impaled with a stimulation electrode and electrically stimulated for $10-15 \mathrm{sec}$ to fire a train of action potentials. The membrane potential of the B4 cell was held at $-70 \mathrm{mV}$, so that the resulting excitatory response could be measured. To test whether excitatory responses in $\mathrm{B} 4$ were caused by the release of serotonin by the $\mathrm{CGC}$, we also recorded responses in the presence of $10^{-5} \mathrm{M}$ methysergide.

\section{RESULTS}

\section{The CGCs as a model for functional neuronal regeneration}

To be able to accurately predict the regenerative response of the CGCs, we used an operation procedure in which the right $\mathrm{CBC}$ was cut and the left $\mathrm{CBC}$ was crushed, thus preventing the right $\mathrm{CGC}$ from regenerating axons into the $\mathrm{CBC}$. We will refer to this procedure as the crush-cut operation. Other operations, which did not involve permanent damage to one of the CGCs, resulted in aberrant and/or inconsistent patterns of regeneration (data not shown) and were not used in these studies. After a crush-cut operation, serotonergic neurites could be traced up to the right (contralateral) buccal ganglion at day 5 after the operation (Fig. $1 A$ ). At day 10, a network of neurites had formed, with neurite branches surrounding many neurons in both buccal ganglia (Fig.
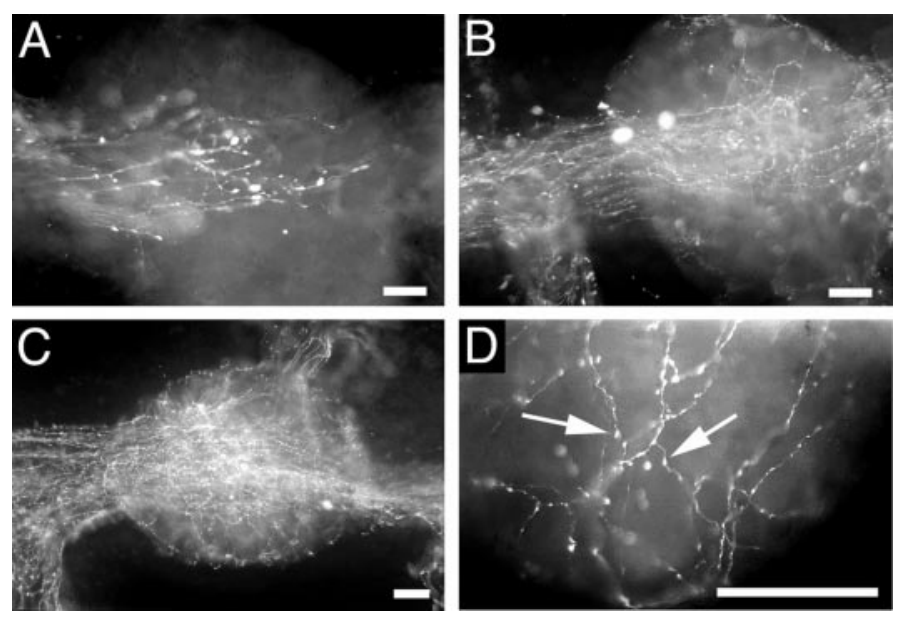

Figure 1. Anti-serotonin whole-mount immunocytochemical staining of the right buccal ganglion during regenerating of the $\mathrm{CGC}$ system. $A$, Five days after a crush-cut operation, serotonergic neurites from the left CGC have passed the left buccal ganglion and started to enter the right buccal ganglion. $B$, At day 10 , a small network of neurites is visible in the right buccal ganglion. $C$, At day 14, serotonergic neurites completely fill the right buccal ganglion, which is now indistinguishable from that of control animals. $D$, At day 14, neurites of the regenerating CGC surround many buccal neurons and are filled with synapse-like varicosities (arrows). Scale bars, $50 \mu \mathrm{m}$.

$1 B)$. At day 14, the density of innervation had further increased (Fig. $1 C$ ), and many target neurons were surrounded by neurites containing small varicosities (Fig. 1D) indicative of synaptic connections.

To test whether functional synapses had formed with buccal target neurons, we performed intracellular recordings at various time points during regeneration. Intact CGCs have monosynaptic connections with the buccal B1, B4, and B6 group neurons (McCrohan and Benjamin, 1980a,b), and modulate feeding behavior (Yeoman et al., 1994a,b). In crush-cut-operated animals, synaptic coupling with B4 was initially absent but returned between days 10 and 14 after the operation (Fig. 2A), showing that the regenerating $\mathrm{CGC}$ is able to reinnervate its original targets.

To test whether CGC regeneration also results in functional recovery, we continuously monitored feeding behavior during regeneration. We quantified the amount of consumed lettuce every second day during regeneration (Fig. 2B). Feeding behavior was initially reduced to $\sim 20 \%$ of that of sham-operated animals and was gradually restored to normal levels after postoperative day 22. To show that this behavioral recovery requires an intact $\mathrm{CBC}$ and is not attributable to plasticity of the feeding network or functionally redundant neural pathways, we also measured feeding behavior in animals with an irreversible bilateral CBC cut. These animals never recovered feeding behavior (Fig. 2C) and died after 3 weeks.

These data demonstrate that on a crush-cut operation to the $\mathrm{CBCs}$, behavioral recovery occurs and this recovery involves the reinnervation of appropriate target neurons by the lesioned CGC. However, it is very likely that other neurons that are also damaged by the operation procedure regenerate projections via the $\mathrm{CBC}$ and contribute to the recovery of the behavior.

\section{The CGCs express several neuropeptides}

To investigate the role of transmitters in CGC regeneration, we first characterized all the peptide transmitters that are expressed by the CGCs. Previous immunocytochemical data (Santama et 

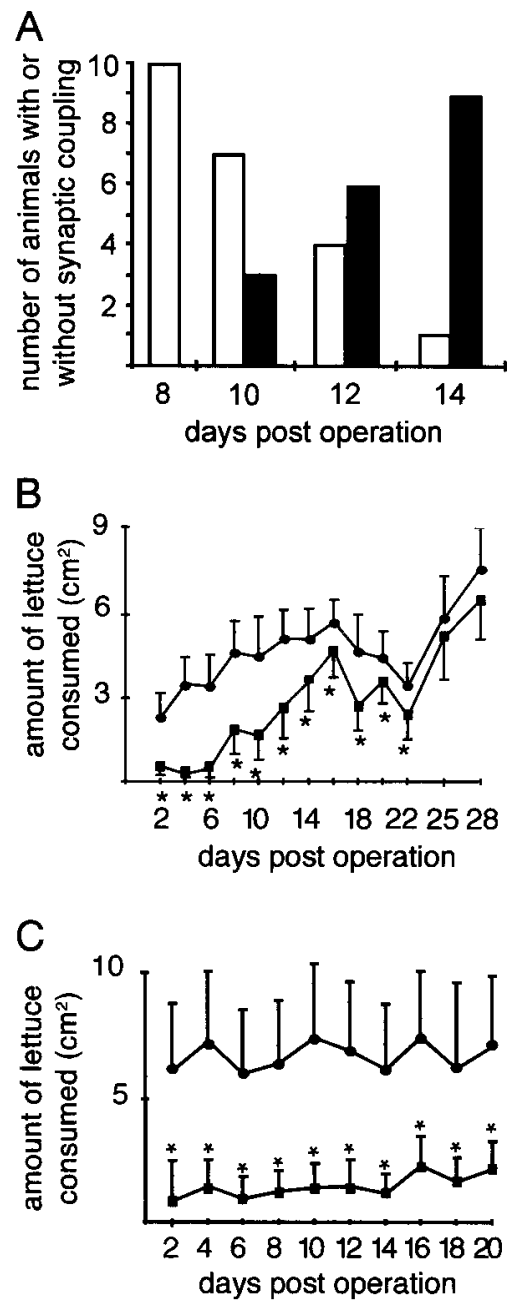

Figure 2. Restoration of synaptic coupling between the left CGC and the left B4 neuron and recovery of feeding behavior in crush-cut-operated animals. $A$, In crush-cut-operated animals, restoration of synaptic coupling occurs between postoperative days 10 and 14 . White bars represent the numbers of animals in which no synaptic contacts were measured; black bars represent the numbers of animals with synaptic contacts between the left CGC and left B4. B, Amounts of lettuce consumed by crush-cut-operated animals (squares) compared with sham-operated animals (circles). C, Amounts of lettuce consumed by animals with both CBCs cut (squares) compared with sham-operated animals (circles). Data points that are significantly different between operated and shamoperated animals are indicated with asterisks (Student's $t$ test; $p<0.05$ ). See Results for further details. Error bars represent SDs.

al., 1994) showed that the CGCs might express members of the myomodulin family of peptides (Kellett et al., 1996). MALDI-MS spectra of individual CGCs (Fig. $3 A$ ) revealed the presence of a molecular mass of $846.3 \mathrm{Da}$, corresponding with the predicted mass of myomodulin A (PMSMLRLamide; predicted mass: 846.1 Da). Enlargement of this area in the MALDI-MS spectrum revealed the masses corresponding to the four other myomodulins, SLSMLRLamide (818.1 vs 818.1 Da, measured vs predicted), GLQMLRLamide (829.3 vs 829.1 Da), SMSMLRLamide (836.6 vs $836.1 \mathrm{Da}$ ), and QIPMLRLamide (868.3 vs $869.1 \mathrm{Da}$ ) (Fig. $3 A$, inset). The fact that myomodulin $\mathrm{A}$ is detected at a higher level than the other myomodulins is in agreement with the fact that the myomodulin precursor contains nine copies of myomodulin A and only one or two copies of each of the other peptides (Kellett et al., 1996). In addition to the myomodulins, three prominent
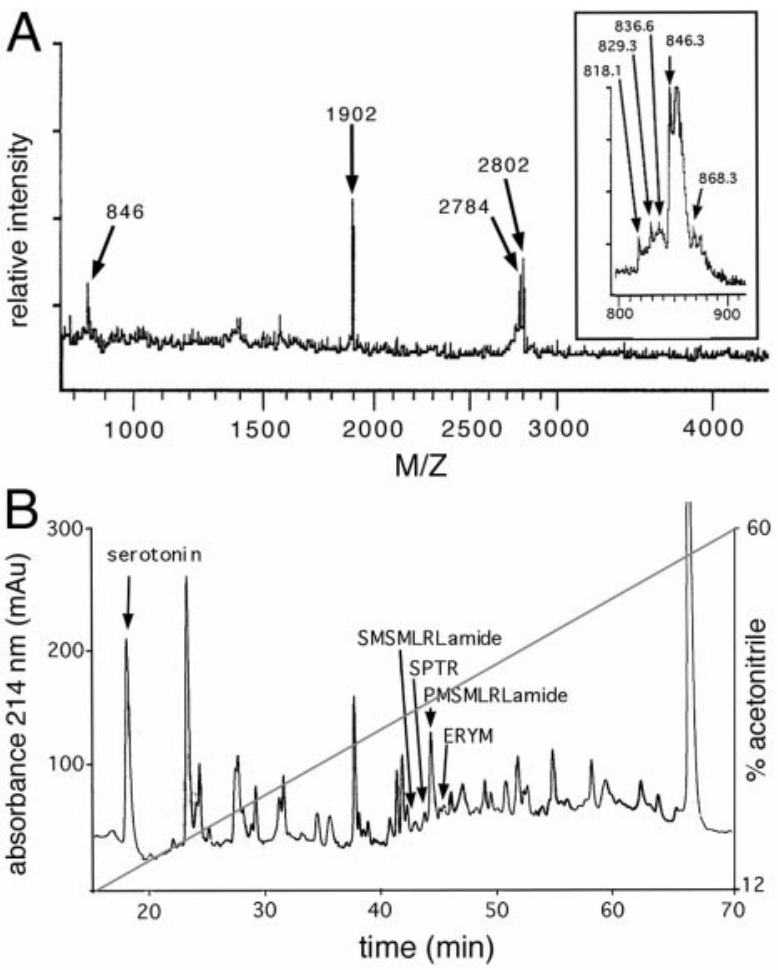

Figure 3. Identification and purification of CGC peptides. $A$, MALDI-MS spectrum of a single CGC. In the spectrum, a molecular mass of $846.3 \mathrm{Da}$ is detected, corresponding with the predicted mass of myomodulin A (PMSMLRLamide; 846.1 Da). Enlargement of this area (inset) reveals molecular ions corresponding with the predicted masses of the four other myomodulins: SLSMLRLamide (818.1 Da), GLQMLRLamide (829.1 Da), SMSMLRLamide (836.1 Da), and QIPMLRLamide $(869.1 \mathrm{Da})$. In addition to the myomodulins, three major unknown masses of 1902,2784 , and $2802 \mathrm{Da}$, respectively, were identified. $x$-axis, mass-tocharge ratio $(M / Z) ; y$-axis, relative ion intensity in arbitrary units. $B$, Chromatogram of the first rpHPLC step in the CGC peptide purification. Co-elution confirmed the presence of serotonin in fraction 18. MALDI-MS mass screening and subsequent Edman degradation of the HPLC fractions revealed the presence of the myomodulins SMSMLRLamide (fraction 42) and PMSMLRLamide (fraction 45), the SPTR peptide (fraction 44), and the ERYM peptide (fractions 46-47). $x$-axis, elution time in minutes; $y$-axes, left, absorbance at $214 \mathrm{~nm}$, and right, percentage acetonitrile.

peaks were observed with masses of 1902, 2784, and $2802 \mathrm{Da}$, respectively (Fig. $3 A$ ). The $18 \mathrm{Da}$ mass difference between the latter two suggests that they might represent pyroglutamateconverted and nonpyroglutamate-converted forms of the same peptide.

To further characterize these unidentified masses in the CGC spectrum, we isolated $1200 \mathrm{CGC}$ somata and purified the peptides using rpHPLC (Fig. 3B). MALDI-MS mass analysis of the rpHPLC fractions combined with Edman degradation resulted in the identification of the 1902 Da peptide and the 2784/2802 Da peptide in fractions 44 and 46, respectively. Further purification of fractions $40-46$ in a next rpHPLC step (data not shown), followed by MALDI-MS analysis and Edman degradation, resulted in a partial 15-amino acid sequence of the 1902 Da peptide (SPTRTDEVLQEASGL; SPTR peptide) and a partial 14amino acid sequence of the 2784/2802 Da peptide (ERYMGICMRKQYNN; ERYM peptide). The latter sequence was probably completely derived from the $2802 \mathrm{Da}$ form of the peptide, whereas the $2784 \mathrm{Da}$ form represents an N-terminally blocked 

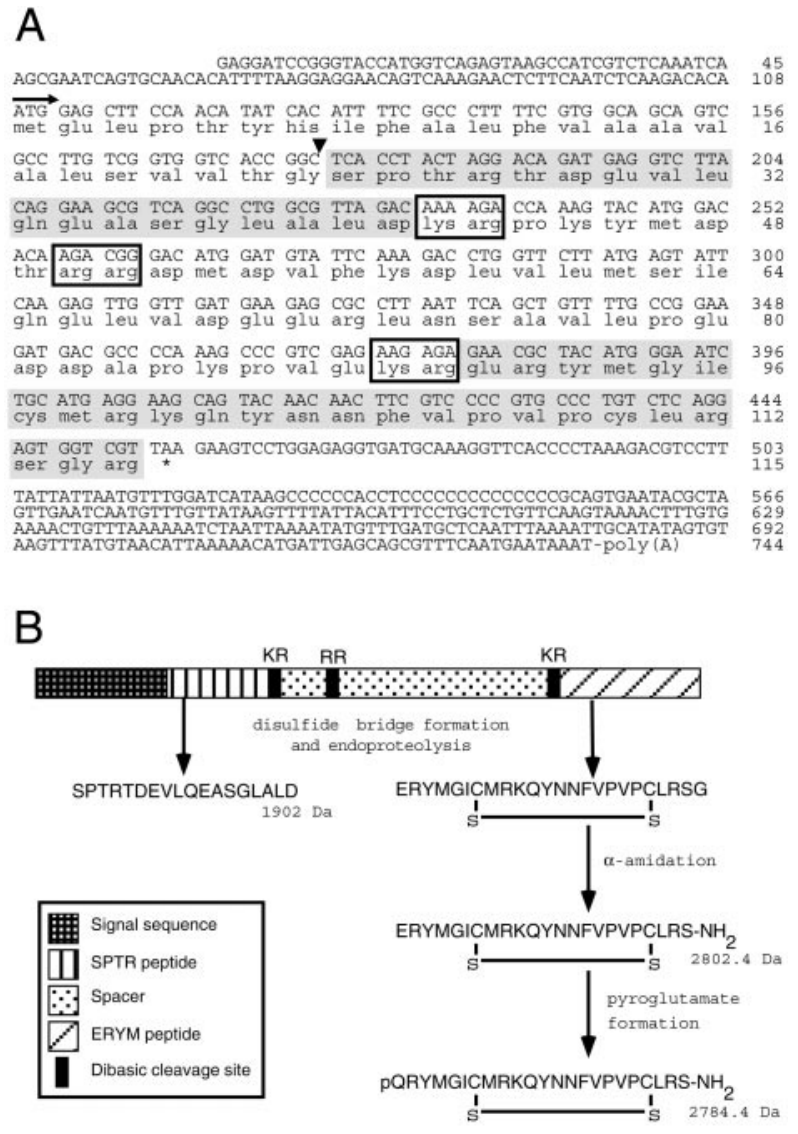

Figure 4. Sequence and processing of the SPTR precursor. $A$, Nucleotide sequence and deduced amino acid sequence of the SPTR preprohormone. Nucleotides and amino acids are numbered at the right. The arrow indicates the start of the signal peptide; the black arrowhead indicates the predicted signal peptide cleavage site; boxes indicate putative dibasic endoproteolytic processing sites; ${ }^{*}$ indicates the stop codon. The SPTR and ERYM peptide domains are shaded. $B$, Structural organization and predicted processing of the SPTR preprohormone. Removal of the signal sequence and subsequent disulfide bridge formation and endoproteolytic processing at dibasic sites yield the mature SPTR peptide (1902.0 Da) and an immature ERYM peptide. The immature ERYM peptide then undergoes $\alpha$-amidation, yielding a mature ERYM peptide of 2802.4 Da, followed by a partial conversion of the N-terminal glutamate residue into a pyroglutamate, resulting in a mature pQRYM-peptide of 2784.4 Da.

pyroglutamate-converted form of the peptide. In addition to the ERYM and SPTR peptides, two of the five myomodulins were detected: SMSMLRLamide in fraction 42 and PMSMLRLamide in fraction 45 . The three remaining myomodulins could not be detected in any of the HPLC fractions because of the impurity of many fractions and the low amounts of peptide present.

On the basis of the amino acid sequence data that was obtained from the ERYM peptide, a degenerate sense oligonucleotide was designed to PCR-screen a $\lambda$ ZAPII cDNA library of the cerebral ganglia. The PCR fragment that was obtained encoded the ERYM peptide, followed by a stop codon and a $3^{\prime}$ UTR. To obtain a full-length cDNA clone, this PCR fragment was used as a probe to isolate individual clones from the library. This resulted in the isolation of a cDNA clone encoding a single precursor protein containing both the ERYM peptide and the SPTR peptide, preceded by a signal sequence (Fig. $4 A$ ). The SPTR and ERYM peptides are separated by a highly acidic peptide region with two Lys-Arg dibasic endoproteolytic processing sites. The predicted mass of the deduced amino acid sequence of the SPTR peptide (i.e., 1902.0 Da) corresponds well with the 1902 Da mass that was detected in the single cell mass spectrum; however, the predicted mass of the ERYM peptide (i.e., 3018.6 Da) differs considerably from either of the detected masses of 2784 and 2802 Da. This difference can only be explained assuming that the $\mathrm{C}$-terminal arginine residue is proteolytically removed, the subsequently exposed glycine residue is converted to a $\mathrm{C}$-terminal amide group, and the two cysteine residues form a disulfide bridge, resulting in a predicted mass of $2802.4 \mathrm{Da}$. Next, the $\mathrm{N}$-terminal glutamate residue must be converted to a pyroglutamate to obtain an additional mass of 2784.4 Da (Fig. 4B). Coelution on HPLC of the native ERYM peptide with a synthetic peptide containing the $\mathrm{N}$-terminal pyroglutamate, the $\mathrm{C}$-terminal amide, and the disulfide bridge (data not shown) further demonstrate that the suggested processing of the SPTR prohormone is correct.

\section{Neurotransmitter expression is regulated during CGC regeneration}

We next asked the question whether transmitter synthesis in the CGCs changes during regeneration. We used in situ hybridization to measure the mRNA expression levels of the SPTR and myomodulin prohormones in the left regenerating CGC. To measure serotonin synthesis, we quantified the mRNA encoding the ratelimiting enzyme in the synthesis of serotonin, i.e., LTRH (Koo et al., 1988; Sun and Zigmond, 1996). We first tested whether our probes recognize the CGCs in intact animals (Fig. $5 A-C$ ). Because the hybridization signal intensity varied between histological sections, we used the hybridization signal of neurons in the pedal ganglia that were not affected by the operation procedure as internal standards for each probe (Fig. $5 D-F$ ). Central ganglia were isolated at days $1,3,5$, and 14 after the operation, and SPTR, myomodulin, and LTRH expression levels were determined by dividing the silver grain density of the left CGC by that of the control neuron and expressing this value as a percentage of that of sham-operated animals (Fig. $5 G-I$ ). At day 5 after the operation, the expression levels of the SPTR gene and the myomodulin gene were significantly downregulated to 53 and $59 \%$ of the control levels, respectively. At day 14 after the operation, the expression levels had reached normal values again and were comparable with those of the control animals. LTRH mRNA expression levels, on the other hand, were not significantly different from control values during the entire period of regeneration.

To confirm the downregulation of the neuropeptide mRNAs relative to LTRH, we used Q-PCR to measure the amounts of SPTR, myomodulin, and LTRH transcripts in intact and regenerating CGCs at day 5 after the operation. Most neuropeptide mRNAs in Lymnaea are abundantly present in axons (van Minnen, 1994), and we indeed observed SPTR and myomodulin transcripts in the initial axon segments of the left CGC (Fig. $5 A, B)$. Therefore, we decided to avoid single cell isolation procedures and to measure the mRNA contents of the CGC neurites within the buccal ganglia instead. Quantification of the mRNAs for SPTR, myomodulin, and LTRH showed that the neuropeptide transcripts are downregulated to 14 and $19 \%$, respectively, compared with the levels of LTRH mRNA (Fig. 5J). These data suggest an even stronger downregulation of SPTR and myomodulin gene expression during regeneration than found with in situ hybridization. In addition, these results might indicate that LTRH mRNA is selectively targeted into regenerating CGC 

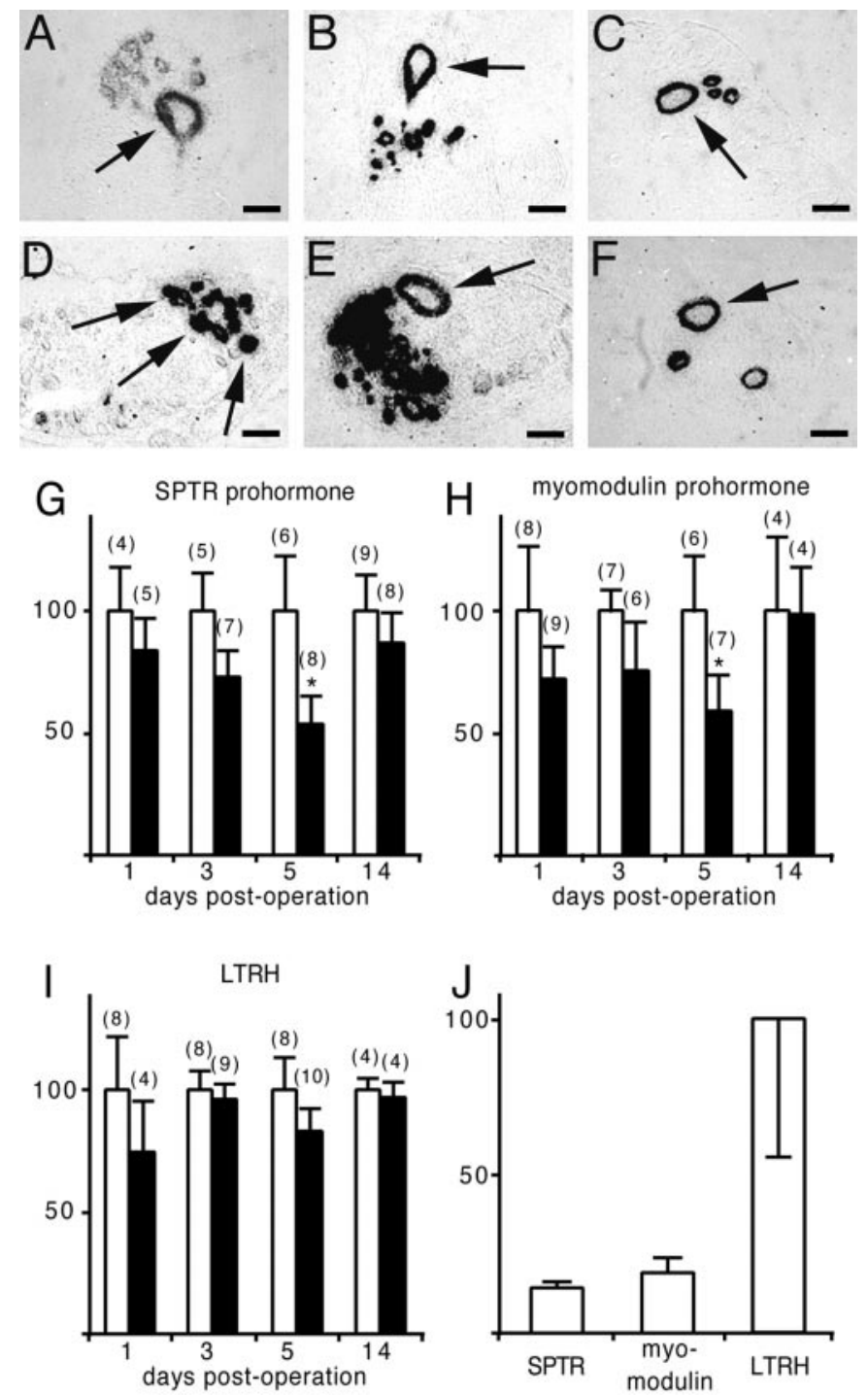

Figure 5. Regulation of SPTR, myomodulin, and LTRH mRNA levels during CGC regeneration. $A-C$, In situ hybridization of tissue sections of the left cerebral ganglion showing expression of SPTR $(A)$, myomodulin $(B)$, and LTRH $(C)$ mRNAs in the left CGC (arrows). $D-F$, In situ hybridization of tissue sections of the pedal ganglia showing expression of SPTR $(D)$, myomodulin $(E)$, and LTRH $(F)$ mRNAs in control neurons (arrows). In these neurons, we never observed changes in mRNA levels as a result of the operation procedures. Scale bars, $75 \mu \mathrm{m}$. $G$, SPTR mRNA levels in the left CGC of sham-operated (white bars) and crush-cutoperated (black bars) animals at days 1, 3, 5, and 14 after the operation. SPTR mRNA levels gradually decreased to $53 \%$ during the first $5 \mathrm{~d}$ of regeneration and had almost completely recovered at day 14 . $H$, Myomodulin mRNA levels in the left CGC of sham-operated (white bars) and crush-cut-operated (black bars) animals at days 1, 3, 5, and 14 after the operation. Myomodulin mRNA levels gradually decreased to $59 \%$ during the first $5 \mathrm{~d}$ of regeneration and had almost completely recovered at day 14. I, LTRH mRNA levels in the left CGC of sham-operated (white bars) and crush-cut-operated (black bars) animals at days 1, 3, 5, and 14 after the operation. LTRH mRNA levels remained high throughout the entire period of regeneration. Error bars indicate SDs. The numbers of animals used per test group are presented in parentheses. ${ }^{*}$ indicates expression levels that are significantly different from controls (one-way ANOVA followed by Bonferroni multiple comparisons test; *p<0.01). J, SPTR and myomodulin mRNA levels, relative to LTRH, in intact (shamoperated) and regenerating (crush-cut-operated) CGC axons within the buccal ganglia at day 5 after the operation. The neuropeptide mRNAs are significantly downregulated to 14 and $19 \%$, respectively, compared with LTRH (Student's $t$ test; $p<0.05$ ). axons, which would also argue for an active role of serotonin in regeneration.

\section{Serotonin modulates CGC neurite outgrowth in vitro}

Because LTRH expression levels remained relatively high during the entire period of regeneration compared with neuropeptide gene expression levels, we hypothesized that serotonin, but not the peptides, might have an active role in the regenerative process. Therefore, the roles of serotonin and the ERYM and SPTR peptides in CGC neurite outgrowth were tested in vitro. We first studied CGC growth cone behavior on focal application of serotonin (Fig. 6). Pressure application of serotonin to CGC growth cones resulted in growth cone collapse and retraction of the neurite over a distance of $50 \pm 12 \mu \mathrm{m}$ (mean $\pm \mathrm{SEM}, n=7$ ) at a rate of $1.4 \pm 0.2 \mu \mathrm{m} / \mathrm{min}$ (Fig. $6 A-C$ ). Application of saline had no effect on the morphology of the growth cones, and neurites continued to advance both during the application and for the following $30 \mathrm{~min}$ (over a distance of $10.6 \pm 5.4 \mu \mathrm{m}$; mean $\pm \mathrm{SEM}$, $n=5$ ). All growth cones that had collapsed because of serotonin application recovered, and five of seven neurites showed outgrowth over the next $3 \mathrm{hr}$. The average outgrowth distance within $3 \mathrm{hr}$ was $55 \pm 12 \mu \mathrm{m}$ (mean $\pm \mathrm{SEM}, n=7$ ) (Fig. $6 D-E$ ). Application of synthetic ERYM and SPTR peptides did not induce growth cone collapse ( $n=5$ and 7 , respectively) (Fig. $6 F-I)$.

Because serotonin seemed to inhibit CGC neurite outgrowth by causing growth cone collapse, we also tested whether freshly isolated CGCs are capable of initiating neurite outgrowth in the continuous presence of serotonin. We plated CGCs together with B4 neurons, i.e., identified follower neurons of the CGCs that respond to serotonin, in the presence and absence of serotonin $\left(10^{-5} \mathrm{M}\right)$. In the presence of serotonin, B4 neurons displayed extensive neurite outgrowth, whereas CGCs did not show any neurite outgrowth at all (Fig. 7A). In the absence of serotonin, both cell types extended processes equally well (Fig. 7B). Thus, serotonin appeared to effectively block neuritogenesis in CGCs.

To determine whether CGCs release serotonin in vitro, we used a "sniffer" cell technique, in which a serotonin-sensitive B4 neuron is held at the tip of a recording electrode as a probe to measure neurotransmitter release from the CGC. Electrophysiological responses were detected in the sniffer cell on electrical stimulation of the CGC when the sniffer cell was juxtaposed on growth cones $(n=2)$, neurites $(n=3)$, and axon stumps $(n=2)$. Depolarization of the CGC in all cases resulted in a depolarization of B4 with an amplitude of $5.7 \pm 1.2 \mathrm{mV}$ and a duration of $61.9 \pm 31.2 \mathrm{sec}($ mean $\pm \mathrm{SD}, n=7)$ (Fig. $8 A$ ). Hyperpolarization of the CGC did not result in an effect in B4 (data not shown), demonstrating that depolarizing responses of B4 were chemical responses and were not caused by electrical contacts. Because the responses measured in $\mathrm{B} 4$ might be attributable to other transmitters being released from the CGC, we also tested whether the B4 response could be blocked by the serotonin receptor antagonist, methysergide. Addition of methysergide $\left(10^{-5} \mathrm{M}\right)$ to the bath prevented depolarization of $\mathrm{B} 4$ in response to CGC stimulation $(n=4)$ (Fig. $8 B)$, demonstrating that it is serotonin that is being released by the $\mathrm{CGC}$.

Knowing that serotonin induces growth cone collapse and inhibits neurite outgrowth of CGCs, and that CGC growth cones and neurites can release serotonin, we next aimed to determine whether a CGC inhibits the outgrowth of another CGC when cultured together in the same dish. When the growth cones of two CGCs approached each other, we observed spontaneous collapse 

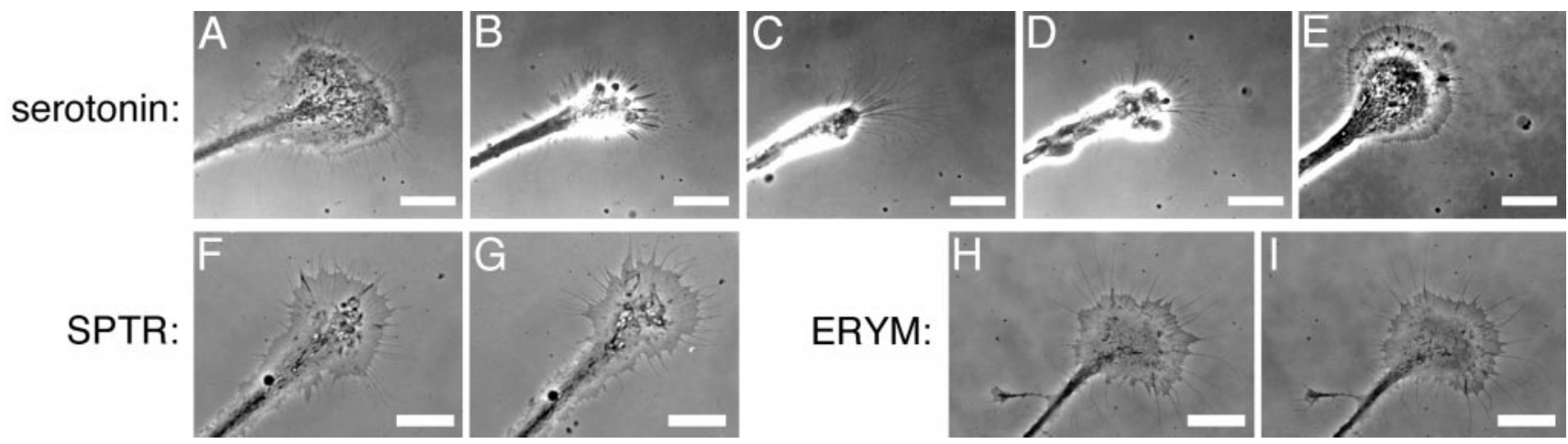

Figure 6. Serotonin, but not neuropeptides, induces growth cone collapse. $A-E$, Photomicrographs of a CGC growth cone during pressure application of serotonin. Serotonin $\left(10^{-5} \mathrm{M}\right)$ was applied for $3 \mathrm{~min}$ at $t=0$. $A$, A healthy CGC growth cone at 20 min before serotonin application. $B$, At $t=4$ min, the growth cone collapsed. $C$, At $t=8 \mathrm{~min}$, the growth cone has retracted. $D$, At $t=12 \mathrm{~min}$, the growth cone starts to recover. $E$, At $t=162 \mathrm{~min}$, the growth cone has fully recovered. $F-I$, Photomicrographs of CGC growth cones during pressure application of the ERYM peptide $(F-G)$ and the SPTR peptide $(H-I)$. Photographs were taken before $(F$ and $H)$ and 7 min after $(G$ and $I)$ pressure application of the peptides $\left(10^{-5} \mathrm{M}\right)$. In both cases, there were no signs of growth cone collapse. Scale bars, $25 \mu \mathrm{m}$.
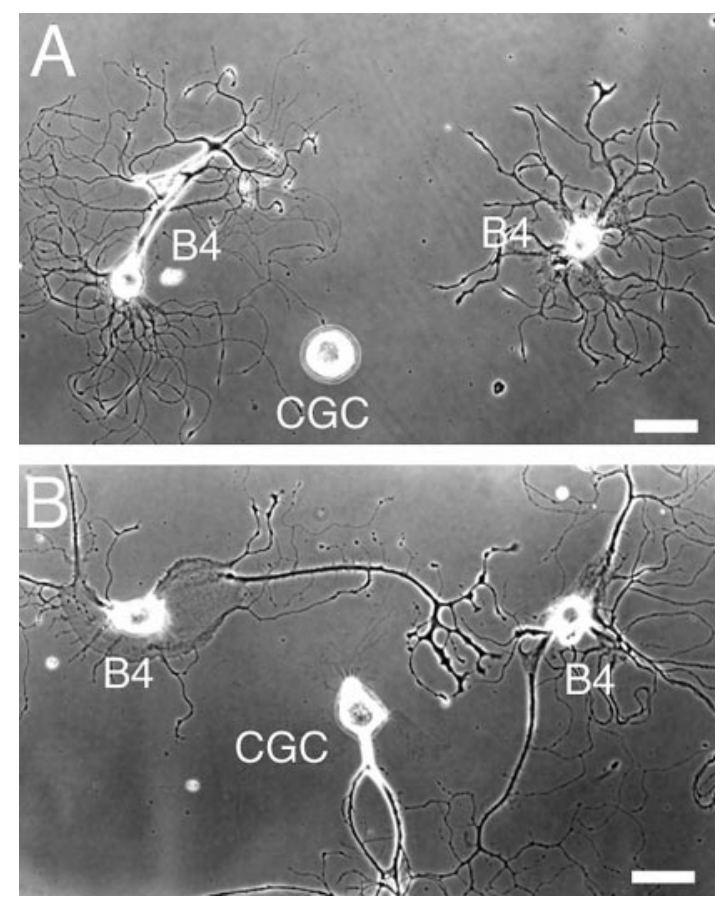

Figure 7. CGC outgrowth is blocked by serotonin. $A$, In the presence of serotonin, the CGC does not initiate neurite outgrowth, whereas B4 neurons have extended multiple neurites. $B$, In the absence of serotonin, the CGC shows neurite outgrowth. Scale bars, $50 \mu \mathrm{m}$.

of one of the growth cones before contact $(n=4)$ (Fig. 9A,B). When a CGC growth cone approached the soma $(n=2)$ or the neurite $(n=1)$ of another CGC, it also collapsed (Fig. 9C,D). To test whether growth cone collapse is caused by the release of serotonin, we stimulated cultured CGCs to fire 5-10 action potentials $(n=9)$ to induce the release of serotonin. Intracellular stimulation always resulted in growth cone collapse (Fig. 9E, F), and this response did not desensitize with repeated stimulation (data not shown). Methysergide $\left(10^{-5} \mathrm{M}\right)$ completely blocked the stimulation-induced collapse response $(n=7)$ (Fig. 9G,H).

\section{DISCUSSION}

Central neurons in the vertebrate brain do not regenerate, and regeneration is often studied in neurons with peripheral projec-

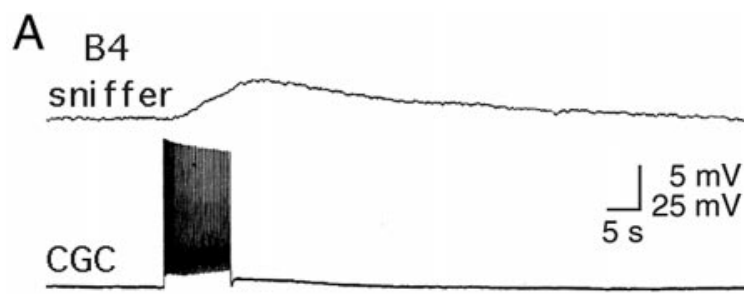

B

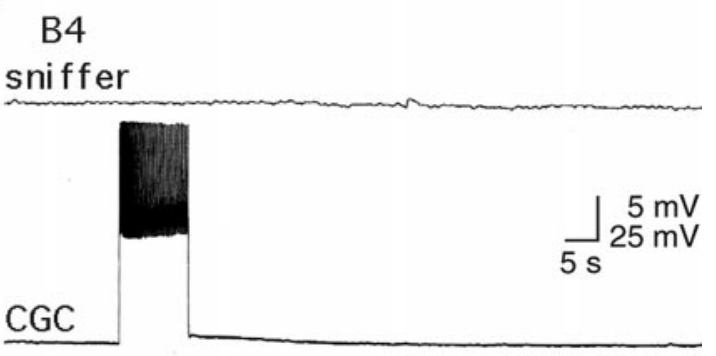

Figure 8. Serotonin release from CGCs in culture as measured with a B4 sniffer cell. $A$, Typical example of a sniffer cell response when B4 is juxtaposed on a CGC growth cone. Electrical stimulation of the CGC (bottom trace) is followed by a depolarizing response in the B4 sniffer neuron (top trace). $B$, In the presence of methysergide $\left(10^{-5} \mathrm{M}\right), \mathrm{B} 4$ does not respond to CGC stimulation.

tions. Here, we tested whether the CGCs of the mollusc Lymnaea stagnalis might offer an alternative to study basic principles of regeneration of central projections, and in particular whether endogenous transmitters play a role in this process. The regenerative properties of the CGCs have been studied in other molluscs to various extents with respect to morphology and functionality (Murphy et al., 1985; Scott and Kirk, 1992; Chiasson et al., 1994), but never before were these findings correlated with molecular changes. Our aim in the present study was to provide a causal relationship between neurotransmitter expression and functional regeneration of the CGCs.

To obtain reproducible patterns of CGC regeneration, we applied crush - cut operations in which the right CGC was permanently damaged, allowing only the left CGC to regenerate. Crush-cut operations resulted in a significant reduction in feeding behavior, which was gradually restored, starting at postoper- 

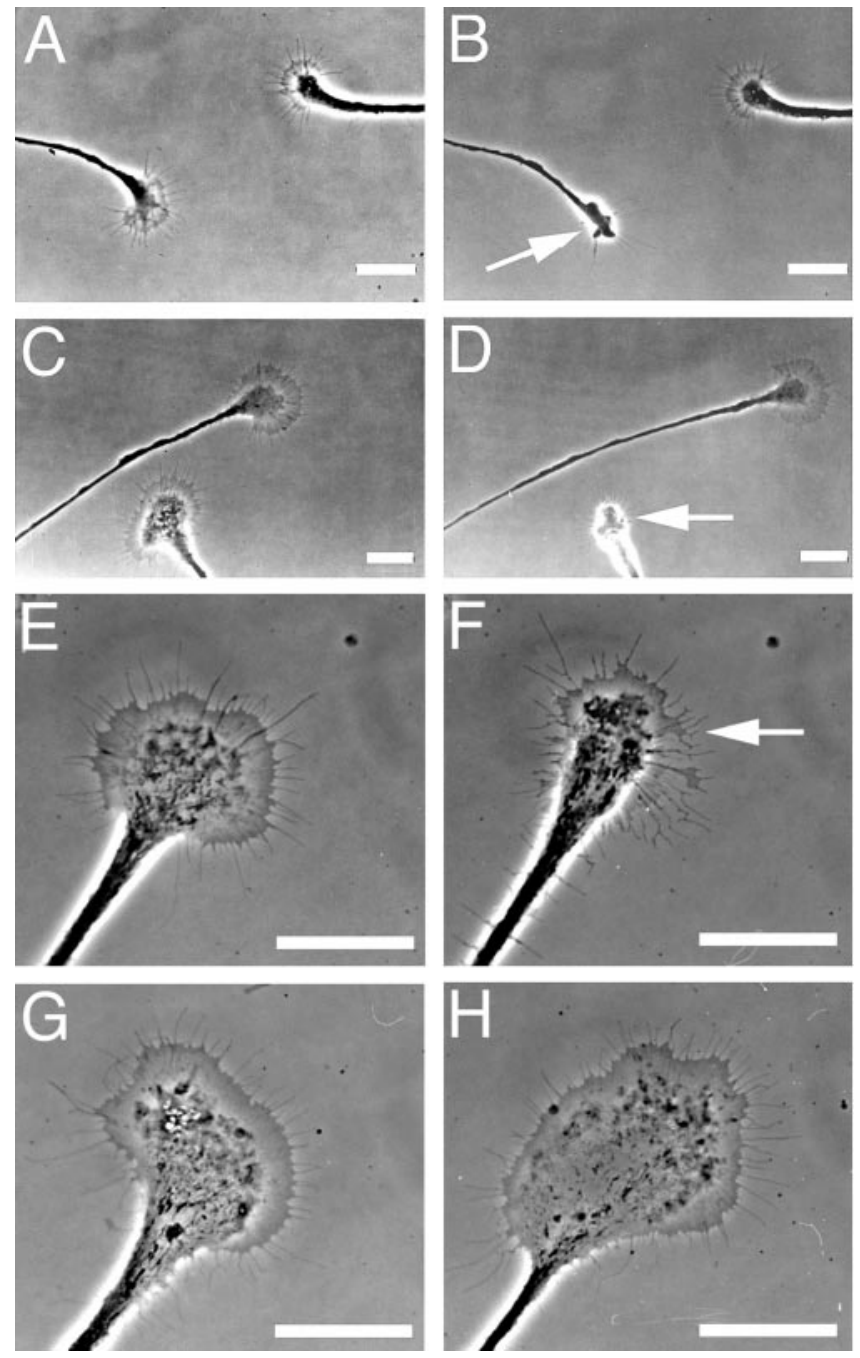

Figure 9. Spontaneous and stimulation-induced release of serotonin results in growth cone collapse. $A$, A CGC growth cone (left) approaches the growth cone of another CGC (right) and $(B)$ spontaneously collapses. $C$, A growth cone of a CGC grows toward a neurite of another CGC and (D) spontaneously collapses before physical contact. $E$, A healthy CGC growth cone before intracellular stimulation by current injection. $F$, After intracellular stimulation, the growth cone collapses. $G, H$, As in $E$ and $F$, but now in the presence of methysergide $\left(10^{-5} \mathrm{M}\right)$. The growth cone does not collapse. Arrows indicate collapsing growth cones. Scale bars, $25 \mu \mathrm{m}$.

ative day 4. At day 5 after the operation, serotonergic neurites were abundantly present in the buccal ganglia. The restoration of synaptic coupling, however, was not observed before postoperative day 10, from which moment recovery of feeding behavior accelerated. The delay between the onset of behavioral recovery (at postoperative day 4) and the onset of synapse formation (at postoperative day 10) has at least three possible explanations. First, humoral release of modulatory transmitters from regenerating CGC neurites might enter the buccal ganglia and could be responsible for the proper execution of feeding behavior between postoperative days 4 and 10, independent of synaptic contacts. Second, the first neurites that reach the target area might form synapses, but their synaptic contacts might be too weak to be measured. In the following days (postoperative days 4-10), an increase in synapse number and synaptic strength might lead to measurable contacts and full recovery of behavior. Third, synaptogenesis with various target neurons involved in the feeding behavior might be differentially regulated in time between postoperative days 4 and 10. Because we measured synaptic coupling with B4 only, it is possible that other target neurons are contacted first, resulting in a partial recovery of feeding behavior.

We next asked which transmitters might be involved in CGC regeneration. We used MALDI-MS to directly demonstrate the presence of known neuropeptides in the CGCs and to guide the purification of novel peptides. The MALDI-MS mass profile of a single CGC confirmed the presence of molecular ions corresponding with the masses of all five myomodulins (Kellett et al., 1996), as well as three unknown peptides with masses of 1902, 2784, and $2802 \mathrm{Da}$, respectively. We confirmed expression of the myomodulin A gene by purifying and sequencing two of the five myomodulins. In addition, we determined the amino acid sequence of the 1902 and 2802 Da peptides. The latter two were named SPTR peptide and ERYM peptide after the N-terminal four amino acid residues of their sequences. The fact that these two peptides were present in roughly equimolar ratio suggested to us that they might be synthesized as parts of a single precursor protein. Indeed, the subsequently cloned cDNA encodes a preprohormone that contains both the SPTR peptide and the ERYM peptide and was named the SPTR prohormone. The SPTR prohormone has no sequence identity to any known protein, except for an apparent sequence ortholog in the leech Hirudo medicinalis (GenBank accession number AAB40925; overall amino acid sequence identity 31\%). The SPTR and ERYM peptides probably function as cotransmitters in the CGC system, because we were able to show that they modulate in vitro the serotonin-induced spiking activity of the CGC itself, as well as of the identified target neuron B4 (data not shown).

We next asked which of the CGC transmitters might play a role in regeneration. It has previously been suggested that transmitters that are only involved in neurotransmission are downregulated on axotomy, whereas others that are involved in regeneration are not (Hökfelt et al., 1994; Zigmond and Sun, 1997). We measured the expression levels of the genes encoding the SPTR and myomodulin precursors and LTRH in the CGC during neurite sprouting, neurite outgrowth, and invasion of the target area, as well as after complete functional recovery (i.e., at postoperative days 1, 3, 5, and 14 , respectively). In the first $5 \mathrm{~d}$, there was a decrease in neuropeptide mRNA levels to $\sim 55 \%$, suggesting that neuropeptides have no function during regeneration. Alternatively, their expression might negatively affect regeneration, and their downregulation may be required to allow a maximal regenerative response. At day 14 after the operation, mRNA levels were comparable with control levels again. The fact that the neuropeptide synthesis was not completely abolished is probably attributable to a branch of the CGC innervating the anterior aorta, the venterobuccal artery, and the lip (Goldschmeding et al., 1981), which was not affected by the operation procedure. In accordance with this, transsection of the $\mathrm{CBC}$ in Aplysia resulted in only a $\sim 50 \%$ reduction of neurotransmitter vesicles transported from the CGC soma at day 7 after the operation (Aletta and Goldberg, 1982). We suggest that the partial loss of synaptic contacts is the reason for this reduction, because when more synapses were affected, a further decrease in the amount of transported vesicles was observed.

In contrast to neuropeptide mRNA levels, LTRH mRNA levels remained normal during the entire period of regeneration. The relatively high levels of LTRH expression are confirmed by quantitative PCR measurements of the mRNA contents of intact and regenerating CGC neurites. This suggested to us that serotonin, 
but not the peptides, might have an active role in the process of regeneration. Many studies have already indicated that serotonin affects outgrowth and growth cone motility of neurons in several ways (Haydon et al., 1984; McCobb et al., 1988; Budnik et al., 1989; Whitaker-Azmitia et al., 1990; Goldberg et al., 1991; Diefenbach et al., 1995). However, our aim in the next set of experiments was to show that the CGCs depend on self-released serotonin to regulate their growth. We first tested whether serotonin directly affects CGC outgrowth and applied serotonin to CGCs in culture. Bath application of serotonin completely blocked neurite outgrowth of CGCs, whereas B4 neurons, which in vivo (Tuersley and McCrohan, 1988) and in vitro (see below) respond to serotonin, showed normal outgrowth. When serotonin was applied focally to CGC growth cones that have already initiated outgrowth in the absence of serotonin, it caused a robust growth cone collapse. The peptides ERYM and SPTR, on the other hand, did not induce growth cone collapse, as would be predicted from the downregulation of their expression. Thus, in outgrowing CGCs, serotonin receptors located on the growth cone surface potentially mediate growth cone collapse and inhibition of neurite outgrowth by auto-released serotonin.

To investigate whether CGCs are able to release serotonin, we electrically stimulated outgrowing CGCs and measured release of transmitters with a B4 sniffer neuron. This experiment showed that depolarization of the CGC is always followed by a depolarization of B4 when held at neurites, growth cones, or axon stumps of the CGC. This depolarization of B4 is completely blocked by the serotonin receptor antagonist methysergide, demonstrating that it is indeed serotonin that is released. Moreover, the complete block of the sniffer cell response by methysergide demonstrates that outgrowing CGCs not only downregulate the synthesis of neuropeptides, but also do not release any modulatory peptides in vitro.

Finally, we studied both spontaneous and stimulation-induced growth cone collapse events of cultured CGCs. When cocultured, CGC growth cones that approached either the soma, the neurites, or the growth cones of another CGC always collapsed before contact, suggesting a response to a released substance. Intracellular stimulation of cultured CGCs also induced growth cone collapse, and this response could be completely blocked by methysergide. These findings suggest that the released substance is serotonin and that it mediates growth cone collapse by acting on serotonin receptors on the growth cone surface.

We suggest that self-released serotonin is actively involved in regeneration of the CGC. In contrast to the neuropeptides, LTRH mRNA levels remain high throughout regeneration, suggesting that serotonin is being actively synthesized during neurite outgrowth. The collapse-inducing effects of serotonin may be used in vivo to regulate the proper branching of CGC neurites. Such a role for serotonin has been suggested previously in other species (Budnik et al., 1989; Diefenbach et al., 1995). Also, serotonin may guide CGC neurites to their target area by inducing collapse of growth cones from behind. This pushing effect has been suggested to be an important property of chemorepulsive factors in general (Tessier-Lavigne and Goodman, 1996) and may be achieved by the spatial control of serotonin release or by a selective distribution of serotonin receptors on CGC growth cones in vivo.

\section{REFERENCES}

Aletta JM, Goldberg DJ (1982) Rapid and precise down regulation of fast axonal transport of transmitter in an identified neuron. Science 218:913-916.
Benjamin PR, Rose RM (1979) Central generation of bursting in the feeding system of the snail, Lymnaea stagnalis. J Exp Biol 80:93-118.

Budnik V, Wu CF, White K (1989) Altered branching of serotonincontaining neurons in Drosophila mutants unable to synthesize serotonin and dopamine. J Neurosci 9:2866-2877.

Chiasson BJ, Baker MW, Croll RP (1994) Morphological changes and functional recovery following axotomy of a serotonergic cerebrobuccal neurone in the land snail Achatina fulica. J Exp Biol 192:147-167.

Croll RP, Chiasson BJ (1989) Postembryonic development of serotoninlike immunoreactivity in the central nervous system of the snail, Lymnaea stagnalis. J Comp Neurol 280:122-142.

Diefenbach TJ, Sloley BD, Goldberg JI (1995) Neurite branch development of an identified serotonergic neuron from embryonic Helisoma: evidence for autoregulation by serotonin. Dev Biol 167:282-293.

Erskine L, McCaig CD (1995) Growth cone neurotransmitter receptor activation modulates electric field-guided nerve growth. Dev Biol 171:330-339.

Filogamo G, Marchisio PC (1971) Acetylcholine system and neural development. Neurosci Res 4:29-64.

Goldberg JI, Mills LR, Kater SB (1991) Novel effects of serotonin on neurite outgrowth in neurons cultured from embryos of Helisoma trivolvis. J Neurobiol 22:182-194.

Goldschmeding JT, van Duivenboden YA, Lodder JC (1981) Axonal branching pattern and coupling mechanisms of the cerebral giant neurones in the snail, Lymnaea stagnalis. J Neurobiol 12:405-424.

Gressens P, Hill JM, Gozes I, Fridkin M, Brenneman DE (1993) Growth factor function of vasoactive intestinal peptide in whole cultured mouse embryos. Nature 362:155-158.

Gressens P, Paindaveine B, Hill JM, Brennemann DE, Evrard P (1997) Growth factor properties of VIP during early brain development. Ann NY Acad Sci 814:152-160.

Haydon PG, McCobb DP, Kater SB (1984) Serotonin selectively inhibits growth cone motility and synaptogenesis of specific identified neurons. Science 226:561-564.

Hökfelt T, Zhang X, Wiesenfeld-Hallin Z (1994) Messenger plasticity in primary sensory neurons following axotomy and its functional implications. Trends Neurosci 17:22-30.

Jiménez JR, van Veelen PA, Li KW, Wildering WC, Geraerts WPM, Tjaden UR, van der Greef J (1994) Neuropeptide expression and processing as revealed by direct matrix-assisted laser desorption ionization mass spectrometry of single neurons. J Neurochem 62:403-407.

Kellett E, Perry SJ, Santama N, Worster BM, Benjamin PR, Burke JF (1996) Myomodulin gene of Lymnaea: structure, expression, and analysis of neuropeptides. J Neurosci 16:4949-4957.

Kemenes G, Elliott CJ (1994) Analysis of the feeding motor pattern in the pond snail, Lymnaea stagnalis: photoinactivation of axonally stained pattern-generating interneurons. J Neurosci 14:153-166.

Koert CJ (2000) Regulation and function of neurotransmitter gene expression in an identified molluscan neuron during functional regeneration. $\mathrm{PhD}$ thesis, Vrije Universiteit Amsterdam.

Koo EH, Hoffman PN, Price DL (1988) Levels of neurotransmitter and cytoskeletal protein mRNAs during nerve regeneration in sympathetic ganglia. Brain Res 449:361-363.

Lauder JM (1990) Ontogeny of the serotonergic system in the rat: serotonin as a developmental signal. Ann NY Acad Sci 600:297-313.

Lauder JM (1993) Neurotransmitters as growth regulatory signals: role of receptors and second messengers. Trends Neurosci 16:233-240.

Lauder JM, Bloom FE (1974) Ontogeny of monoamine neurons in the locus coeruleus, Raphe nuclei and substantia nigra of the rat. I. Cell differentiation. J Comp Neurol 155:469-481.

Lipton SA, Kater SB (1989) Neurotransmitter regulation of neuronal outgrowth, plasticity and survival. Trends Neurosci 12:265-270.

Lipton SA, Frosch MP, Phillips MD, Tauck DL, Aizenman E (1988) Nicotinic antagonists enhance process outgrowth by rat retinal ganglion cells in culture. Science 239:1293-1296.

Magistretti PJ, Morrison JH, Shoemaker WJ, Sapin V, Bloom FE (1981) Vasoactive intestinal polypeptide induces glycogenolysis in mouse cortical slices: a possible regulatory mechanism for the local control of energy metabolism. Proc Natl Acad Sci USA 78:6535-6539.

Mattson MP (1988) Neurotransmitters in the regulation of neuronal cytoarchitecture. Brain Res 472:179-212.

McCobb DP, Cohan CS, Connor JA, Kater SB (1988) Interactive effects of serotonin and acetylcholine on neurite elongation. Neuron $1: 377-385$

McCrohan CR, Benjamin PR (1980a) Patterns of activity and axonal projections of the cerebral giant cells of the snail, Lymnaea stagnalis. $\mathrm{J}$ Exp Biol 85:149-168.

McCrohan CR, Benjamin PR (1980b) Synaptic relationships of the cerebral giant cells with motoneurones in the feeding system of Lymnaea stagnalis. J Exp Biol 85:169-186.

Murphy AD, Barker DL, Loring JF, Kater SB (1985) Sprouting and functional regeneration of an identified serotonergic neuron following axotomy. J Neurobiol 16:137-151.

Said SI, Mutt V (1970) Polypeptide with broad biological activity: isolation from small intestine. Science 169:1217-1218. 
Santama N, Brierley M, Burke JF, Benjamin PR (1994) Neural network controlling feeding in Lymnaea stagnalis: immunocytochemical localization of myomodulin, small cardioactive peptide, buccalin, and FMRFamide-related peptides. J Comp Neurol 342:352-365.

Scott ML, Kirk MD (1992) Recovery of consummatory feeding behavior after bilateral lesions of the cerebral-buccal connectives in Aplysia californica. Brain Res 585:272-274.

Smit AB, Spijker S, Geraerts WP (1992) Molluscan putative prohormone convertases: structural diversity in the central nervous system of Lymnaea stagnalis. FEBS Lett 312:213-218.

Smit AB, Spijker S, van Minnen J, Burke JF, De Winter F, van Elk R, Geraerts WP (1996) Expression and characterization of molluscan insulin-related peptide VII from the mollusc Lymnaea stagnalis. Neuroscience 70:589-596.

Spijker S, Smit AB, Martens GJ, Geraerts WP (1997) Identification of a molluscan homologue of the neuroendocrine polypeptide 7B2. J Biol Chem 272:4116-4120.

Sun Y, Zigmond RE (1996) Involvement of leukemia inhibitory factor in the increases in galanin and vasoactive intestinal peptide mRNA and the decreases in neuropeptide $\mathrm{Y}$ and tyrosine hydroxylase mRNA in sympathetic neurons after axotomy. J Neurochem 67:1751-1760.

Syed NI, Bulloch AGM, Lukowiak K (1990) In vitro reconstruction of the respiratory central pattern generator of the mollusk Lymnaea. Science 250:282-285.

Tessier-Lavigne M, Goodman CS (1996) The molecular biology of axon guidance. Science 274:1123-1133

Tuersley MD, McCrohan CR (1988) Serotonergic modulation of patterned motor output in Lymnaea stagnalis. J Exp Biol 135:473-486.

van der Steen WJ (1969) A method for breeding and studying freshwater snails under continuous water change, with some remarks on growth and reproduction in Lymnaea stagnalis. Neth J Zool 19:131-139. van Kesteren RE, Tensen CP, Smit AB, van Minnen J, van Soest PF, Kits KS, Meyerhof W, Richter D, van Heerikhuizen H, Vreugdenhil E, Geraerts WPM (1995) A novel G protein-coupled receptor mediating both vasopressin- and oxytocin-like functions of Lys-conopressin in Lymnaea stagnalis. Neuron 15:897-908.

van Minnen J (1994) Axonal localization of neuropeptide-encoding mRNA in identified axons of the snail Lymnaea stagnalis. Cell Tissue Res 276:155-161.

Whitaker-Azmitia PM, Shemer AV, Caruso J, Molino L, Azmitia EC (1990) Role of high affinity serotonin receptors in neuronal growth. Ann NY Acad Sci 600:315-330.

Wong RG, Hadley RD, Kater SB, Hauser GC (1981) Neurite outgrowth in molluscan organ and cell cultures: the role of conditioning factor(s). J Neurosci 1:1008-1021.

Yeoman MS, Pieneman AW, Ferguson GP, Ter Maat A, Benjamin PR (1994a) Modulatory role for the serotonergic cerebral giant cells in the feeding system of the snail, Lymnaea. I. Fine wire recording in the intact animal and pharmacology. J Neurophysiol 72:1357-1371.

Yeoman MS, Kemenes G, Benjamin PR, Elliott CJ (1994b) Modulatory role for the serotonergic cerebral giant cells in the feeding system of the snail, Lymnaea. II. Photoinactivation. J Neurophysiol 72:1372-1382.

Yeoman MS, Brierley MJ, Benjamin PR (1996) Central pattern generator interneurons are targets for the modulatory serotonergic cerebral giant cells in the feeding system of Lymnaea. J Neurophysiol 75:11-25.

Zheng JQ, Felder M, Connor JA, Poo MM (1994) Turning of nerve growth cones induced by neurotransmitters. Nature 368:140-144.

Zigmond RE (1998) Molecular signals in nerve regeneration. Soc Neurosci Abstr 28:684.

Zigmond RE, Sun Y (1997) Regulation of neuropeptide expression in sympathetic neurons. Ann NY Acad Sci 814:181-197. 